\title{
Carnitine palmitoyltransferase 1A P479L and infant death: policy implications of emerging data
}

\author{
Alison E. Fohner, $\mathrm{PhD}^{1}$, Nanibaa' A. Garrison, $\mathrm{PhD}^{2,3}$, Melissa A. Austin, $\mathrm{PhD}^{4}$ \\ and Wylie Burke, MD, PhD
}

Carnitine palmitoyltransferase 1 isoform A (CPT1A) is a crucial enzyme for the transport of long-chain fatty acids into the mitochondria. The CPT1A p.P479L variant is found in high frequencies among indigenous populations residing on the west and north coasts of Alaska and Canada and in northeast Siberia and Greenland. Epidemiological studies have reported a statistical association between P479L homozygosity and infant death in Alaska Native and Canadian Inuit populations. Here, we review the available evidence about the P479L variant and apply to these data the epidemiological criteria for assessing causal associations. We found insufficient evidence to support a causal association with infant death and, further, that if a causal association is present, then the genotype is likely to be only

The discovery of a novel variant of carnitine palmitoyltransferase 1 isoform A (CPT1A), p.P479L, occurring in high frequency among indigenous populations residing on the west and north coasts of Alaska, in northern Canada, and in northeastern Siberia,${ }^{1-4}$ has generated considerable interest. A variant of this gene previously identified in North American Hutterite populations, p.G710E, results in loss of enzyme function; in the homozygous state the p.G710E variant has been associated with childhood hypoglycemia and infant death. ${ }^{5,6}$ Therefore, the potential health effects of the P479L variant are of concern. Four epidemiological studies performed in Alaska and Canada have reported a statistical association between P479L homozygosity and infant death, suggesting that the genotype may have important public health significance. . $3,3,7,7,8$

However, the available evidence regarding P479L homozygosity and infant death is insufficient to support a causal association and suggests that if a causal association is present, then the genotype is likely to be only one of a complex set of factors contributing to an increased risk of infant death. We review here what is known and not known about the P479L variant and argue that public health action is premature. Instead, a collaborative effort is needed to address the remaining uncertainties about this genotype. one of a complex set of factors contributing to an increased risk of infant death. We conclude that additional research is needed to clarify the observed association and to inform effective preventative measures for infant death. In light of these findings, we discuss the policy implications for public health efforts because policies based on the observed association between P479L homozygosity and infant death data are premature.

Genet Med advance online publication 26 January 2017

Key Words: Alaska Native; carnitine palmitoyltransferase 1 isoform A (CPT1A); First Nations; sudden infant death

\section{BACKGROUND: FATTY ACID METABOLISM AND CPT1A GENE VARIANTS}

When glycogen stores are exhausted as a result of fasting or prolonged exercise, fatty acids are released from adipose tissue to be oxidized in mitochondria to form ketones as the main source of cellular energy. ${ }^{9}$ CPT1A plays an important role in this process by catalyzing the substitution of carnitine for the CoA group conjugated to a fatty acid and allowing transport of long-chain fatty acids across the mitochondrial membrane for $\beta$-oxidation and conversion into ketones. ${ }^{6,9,10} \mathrm{CPT} 1 \mathrm{~A}$ expression is subject to diet and hormonal regulation; ${ }^{11}$ malonyl-CoA is thought to inhibit CPT1A activity whereas a diet rich in polyunsaturated fatty acids may upregulate CPT1A expression. ${ }^{12-14}$ The efficiency of the CPT1A pathway is assessed by calculating the ratio of free carnitine to free long-chain acylcarnitine $(\mathrm{CO} /$ $(\mathrm{C} 16+\mathrm{C} 18)) .{ }^{11}$ Loss of CPT1A activity increases this ratio. ${ }^{11}$

Much of what is known about CPT1A comes from the wellcharacterized p.G710E variant that is found at a frequency of 0.07 in the Hutterite population but is rare in other populations. ${ }^{5}$ The p.G710E gene variant results in complete loss of catalytic function of CPT1A by altering the active site of the enzyme, although it does not affect protein synthesis or localization. ${ }^{6}$ The resulting severe clinical symptoms are referred to as classic

${ }^{1}$ Department of Genetics, School of Medicine, Stanford University, Stanford, California, USA; ${ }^{2}$ Treuman Katz Center for Pediatric Bioethics, Seattle Children's Research Institute, Seattle, Washington, USA; ${ }^{3}$ Department of Pediatrics, Division of Bioethics, School of Medicine, University of Washington, Seattle, Washington, USA; ${ }^{4}$ Department of Epidemiology, University of Washington, Seattle, Washington, USA; ${ }^{5}$ Department of Bioethics and Humanities, School of Medicine, University of Washington, Seattle, Washington, USA. Correspondence: Alison E. Fohner (afohner@stanford.edu) 
CPT1A deficiency: hypoketotic hypoglycemia, liver failure, hepatomegaly, seizures, and coma, with complications often triggered by fasting, fever, or prolonged exercise. ${ }^{5}$ Although the condition can be fatal without treatment and recurrent events can result in neurologic sequelae, a special low-fat diet supplemented with medium-chain fatty acids effectively prevents the appearance of clinical symptoms. ${ }^{5}$ The risk of a hypoketotic event is highest in the first 5 years of life. ${ }^{5}$ Besides the p.G710E variant, several other isolated instances of severe CPT1A deficiency have been reported. ${ }^{11,15,16}$ Newborn screening to identify infants with classic CPT1A deficiency is mandated in 32 states of the United States and is available or likely to be detected as a result of other tests in 16 more states and 5 Canadian provinces. ${ }^{17,18}$

In contrast to the p.G710E variant, the P479L gene variant causes a substitution of leucine for proline in a binding site for malonyl-CoA, reportedly resulting in residual CPT1A function of approximately $25-50 \%{ }^{11,19,20}$ The P479L protein seems to have reduced affinity for the endogenous transferase inhibitor, malonyl-CoA; it is also thermolabile and unstable and experiences rapid degradation..$^{13}$ The frequency of the variant ranges from 0.68 to 0.85 among some indigenous populations in Canada, Alaska, and Siberia ${ }^{21,22}$ (Table 1). It is especially common in Nunavut, Canada and in western Alaska, where most of the population is of Inuit ancestry; the variant is exceedingly rare in other populations. ${ }^{21,22}$

\section{ASSOCIATION BETWEEN P479L AND INFANT DEATH}

To date, four small-scale population-based studies have reported on the association between the P479L variant and risk of infant mortality: two among Alaska Native (AN) infants; $;{ }^{1,8}$ one in Canada's three north territories, with a follow-up analysis in Nunavut, Canada $;{ }^{23}$ and one in First Nations (FN) infants in British Columbia, Canada. ${ }^{3}$ Here, we examine the strength of the evidence and conclusions presented in each of these studies separately and then assess the collective evidence according to epidemiologic criteria for a causal association. ${ }^{24}$

\section{Studies of Alaska Native infants}

The first study performed in Alaska examined the incidence of infant mortality within the first year by linking individual CPT1A genotype data of $616 \mathrm{AN}$ infants with birth certificates and, if available, death certificates. ${ }^{1}$ The death certificates listed the cause of death for seven infants, with five being P479L homozygous. Five of the seven infants had respiratory infections at the time of death and all infants showed some signs of infection, but respiratory infections were listed as the cause of death for only one P479L homozygous infant and the two heterozygous infants. ${ }^{1}$ The results of this study demonstrate a statistically significant association between CPT1A genotype and infant mortality (Table 2). The sample size for infant deaths was very small $(n=7)$, suggesting that the association should be interpreted with caution. Furthermore, one of the deaths of an infant with P479L homozygosity was adjudicated as a homicide, which is not a biologically plausible consequence of the genetic variant. ${ }^{1}$ The wide variability in allele frequency by geographical region suggests possible population stratification, which has been associated with a higher false-positive rate. ${ }^{25}$ When the association analysis was repeated for infants from the western and northern regions only, where the variant is found at high frequency, the odds ratio (OR) was 5.0 and no longer statistically significant (95\% confidence interval (CI): 0.6 to $42.6, P=0.12$ ).

In a second study of AN infants, the frequency of the P479L variant was compared in 110 infants who died before 1 year of age and 395 infants who lived. ${ }^{8}$ After adjusting for three of the variables that have previously been associated with increased risk of infant mortality, maternal prenatal alcohol or tobacco use, maternal education, and involvement of a father figure, the distribution of the P479L variant was not significantly different between cases and controls. ${ }^{8}$ In fact, the authors concluded that sudden infant death was less likely to be the cause of mortality for P479L homozygous infants than it was for infants heterozygous or homozygous for the reference variant, although this finding was not statistically significant $(\mathrm{OR}=0.50 ; 95 \% \mathrm{CI}$ : $0.22-1.1)$. However, P479L homozygosity was associated with increased risk of death due to infection $(\mathrm{OR}=2.9 ; 95 \% \mathrm{CI}$ : 1.0 8.0). This finding is consistent with a previous study of Alaska Medicaid billing claims that found a small increase in lower respiratory infections (mean: 5.5 vs. 3.5 episodes) and otitis media (prevalence: 86 vs. $69 \%$ ) among AN children from birth to age 2.5 years who had P479L homozygosity and resided in nonhub communities. ${ }^{23,26}$ Further studies are needed to determine whether infectious disease aggravates any hypoglycemic risk associated with the P479L variant as it does for the p.G710E variant. $^{5}$

\section{Studies of Canadian Inuit and First Nations Infants}

Using population prevalence data, a study performed in northern Canada provided data on the association between P479L homozygosity and risk of sudden infant death syndrome, sudden unexplained death in infancy, and death due to infection (Table 2). ${ }^{4}$ Among all homozygous P479L sudden infant death syndrome and sudden unexplained death in infancy cases, at least one sleep-related risk factor was also present, including nonsupine sleeping and bed sharing. ${ }^{4}$ Similar to the results from the first study in Alaska, ${ }^{1}$ the ORs for risk of infant death with P479L homozygosity were significant but had wide CIs (Table 2).

Nunavut has an infant mortality rate that is three times the Canadian national average; it also has a high prevalence of $\mathrm{P} 479 \mathrm{~L}$ homozygosity. ${ }^{4}$ However, the P479L variant was not found to be in Hardy-Weinberg equilibrium in the Nunavut region overall, indicating that the population substructure could affect association results. Stratifying the analysis by regions within Nunavut weakened the genetic association. Notably, in the Kitikmeot region, with a high prevalence of the P479L variant (0.73), the OR was 1.09 (95\% CI: 0.19-11.47). Furthermore, genotype data were available for only 35 of the 81 infants, 17 of whom were 
Table 1 Frequency of CPT1A p.P479L genotypes and alleles among infants born in the Northern territories of Canada and Alaska with comparisons to African American and European American samples

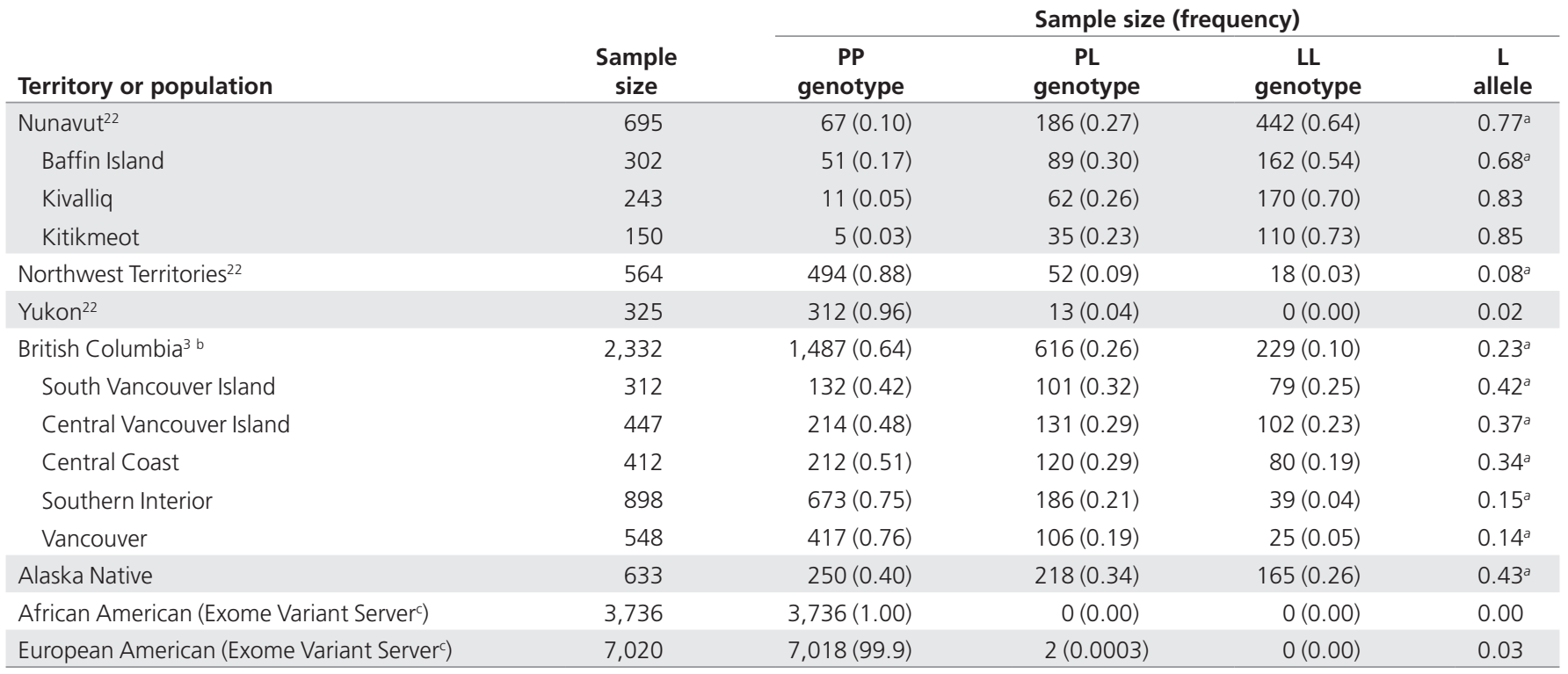

aGenotype frequencies deviate from Hardy-Weinberg equilibrium $(P<0.05)$. begions not mutually exclusive. chttp://evs.gs.washington.edu/EVS/.

Table 2 Frequencies of CPT1A p.P479L genotypes among cases of unexpected infant deaths and among all infants, summarized from association analyses

\begin{tabular}{|c|c|c|c|c|c|c|c|c|}
\hline$\frac{\text { Study }}{\text { P479L genotype }}$ & \multicolumn{2}{|c|}{$\begin{array}{l}\text { Alaska } \\
\text { Native }^{1}\end{array}$} & \multicolumn{2}{|c|}{$\begin{array}{c}\text { Nunavut, Canada } \\
1999-2011^{4}\end{array}$} & \multicolumn{2}{|c|}{$\begin{array}{l}\text { First Nations, } \\
\text { South Vancouver Island }\end{array}$} & \multicolumn{2}{|c|}{$\begin{array}{l}\text { First Nations, Central } \\
\text { Vancouver Island }{ }^{3}\end{array}$} \\
\hline PP and PL combined & $2(28.6)$ & $462(75.9)$ & $5(14.3)$ & $253(36.4)$ & $9(64.3)$ & $233(74.7)$ & $6(42.9)$ & $345(77.2)$ \\
\hline PP (homozygote) & $0(0.0)$ & $245(40.2)^{a}$ & $0(0.0)$ & & $5(35.7)$ & & $4(28.6)$ & \\
\hline Total & $7(100.0)$ & $609(100.0)$ & $35(100.00)$ & $695(100.0)$ & $14(100.0)$ & $312(100.0)$ & $14(100.0)$ & $447(100.00)$ \\
\hline $\begin{array}{l}\text { Odds ratio ( } 95 \% \\
\text { confidence } \\
\text { interval); } P \text { value }\end{array}$ & \multicolumn{2}{|c|}{$7.6(1.5-38.9) ; P=0.01$} & \multicolumn{2}{|c|}{$3.43(1.30-11.47) ; P=0.006$} & \multicolumn{2}{|c|}{$1.64(0.42-5.63) ; P=0.55$} & \multicolumn{2}{|c|}{$4.51(1.59-13.26) ; P=0.014$} \\
\hline
\end{tabular}

aFrequencies do not add to $75.9 \%$ due to rounding.

genotyped after death at the request of the medical examiner, which may have introduced bias based on which infants were genotyped. The authors caution that these data neither confirm nor rule out a role of the P479L variant in infant death because the study size was small and because other known risk factors for infant death, which include high rates of nonsupine sleeping and bed sharing, maternal smoking, home tobacco exposure, and prematurity, are more common in Nunavut than in other regions of Canada. ${ }^{4}$

A study of FN infants in British Columbia examined the CPT1A genotype and $\mathrm{C} 0 /(\mathrm{C} 16+\mathrm{C} 18)$ ratios from all 2,332 newborn blood spots from 2004 and an additional 51 unexplained cases of infant death from 1999 to 2009 (Table 2). ${ }^{3}$ They found that frequencies of P479L homozygosity varied widely across the three regions (Table 1). Additionally, they found that the $\mathrm{C} 0 /(\mathrm{C} 16+\mathrm{C} 18)$ ratios in newborns with P479L homozygosity were significantly higher than those in newborns heterozygous and homozygous for the reference variant $(P<0.0001)$. However, the ratios were well below those found for infants with classic CPT1A deficiency (50th percentile in the mid-20s for P479L homozygotes compared with 105 for infants with classic CPT1A deficiency ${ }^{16}$ ). No difference was seen between the ratios of the $11 \mathrm{P} 479 \mathrm{~L}$ homozygotes who experienced infant death and the ratios of the 227 infants who did not. ${ }^{3}$

When all three regions of British Columbia were examined together, P479L homozygosity was significantly associated with sudden infant death. When the three regions were analyzed separately, a significant association was found in Central Vancouver Island but not in South Vancouver Island (Table 2), and no cases of infant death were reported in the Central Coast 
region, which had the third highest frequency of the P479L variant (Table 1). These data provide further evidence of the impact of stratification and clustering on the results.

\section{OVERALL ASSESSMENT OF CAUSALITY BETWEEN P479L AND INFANT DEATH}

Epidemiological criteria for establishing a causal association include strength and consistency of the association, temporal sequence, dose response, biological plausibility, and alternative causal explanations..$^{24}$ Each of these principles is considered in the context of what is currently known about the $\mathrm{P} 479 \mathrm{~L}$ variant and infant death, including the evidence presented in the aforementioned four studies.

\section{Strength and consistency of the association}

Taken together, the available association results provide preliminary evidence that P479L homozygosity is associated with increased risk of infant death among AN and Inuit populations. ${ }^{1,3,4}$ The ORs in the four studies reviewed here are high, of similar magnitude, and statistically significant. However, the case sample sizes in all four studies are small $(n=7, n=35, n=51$, and $n=110$, respectively) $)^{1,3,4,8}$ and the OR CIs are wide, providing imprecise estimates of the actual magnitude of the association.

In addition, the genotype frequencies in these populations deviate from Hardy-Weinberg equilibrium, demonstrating an excess of both the homozygous P479L genotype and the homozygous reference genotype and showing a dearth of heterozygotes. ${ }^{1,3,22}$ Further comparisons are difficult because study parameters and definitions are inconsistent across the four studies. The age range considered for infant death was younger than 1 year of age ${ }^{1,4,8}$ or younger than 2 years of age, ${ }^{3}$ and the end points included sudden unexplained infant death, ${ }^{3,4}$ death resulting from infectious disease, ${ }^{4,8}$ or all cases of infant death together. ${ }^{1,8}$ Thus, the available data offer support for an association but uncertainty about its strength and consistency.

\section{Temporal sequence of events}

In causal associations, the risk exposure should occur prior to the health outcome. The development of hypoglycemia mediated by P479L homozygosity during infancy might provide some useful evidence related to this criterion. One study reported the fasting of five AN children who were P479L homozygous. ${ }^{27}$ During fasting, the levels of long-chain acylcarnitine and free carnitine changed less than in children with normal metabolism. Two of the children, both with a history of hypoglycemic symptoms, developed hypoglycemia, but the three other children maintained normal blood glucose levels $(>50 \mathrm{mg} / \mathrm{dl}),{ }^{27}$ thus raising questions about the association of P479L homozygosity with hypoglycemia during fasting. The fasting study was terminated early at $18 \mathrm{~h},{ }^{27}$ and the small sample size and lack of controls make it difficult to draw meaningful conclusions from these data.

\section{Dose-response relationship}

This criterion is not relevant for an association between the P479L allele and infant death. P479L heterozygotes are expected to have 50 to $75 \%$ of the enzyme level found in people homozygous for the reference variant, with correspondingly increased $\mathrm{C} 0 /(\mathrm{C} 16+\mathrm{C} 18)$ ratios. $^{3,19}$ Infants with the heterozygous genotype are not expected to be at increased risk for sudden infant death, ${ }^{3}$ and the reported associations are with the P479L homozygous genotype only.

\section{Biological plausibility and consistency with other knowledge}

The effect of the P479L variant on enzyme function is an important consideration for the biological plausibility of a causal association with infant death. The p.G710E variant results in a completely inactive protein. ${ }^{28}$ By contrast, the P479L variant reduces protein stability and inhibition by malonyl $\mathrm{CoA}^{13}$ but does not appear to affect the active site for acyl-CoA binding specifically. ${ }^{19}$ Therefore, the protein that is present in the cell should be active and could be more efficient than protein from the reference variant due to decreased sensitivity to malonyl$\mathrm{CoA}$ inhibition and upregulation with a diet rich in polyunsaturated fatty acids. ${ }^{13,19}$ The impact of the P479L variant on catalytic efficiency thus would depend on the extent to which it reduces $\mathrm{CPT} 1 \mathrm{~A}$ accumulation.

Frequency of the variant is also a consideration. If a genotype is associated with a significant increase in infant death, it would be expected to have a low frequency in the population and to decrease over time as a result of decreased reproductive fitness. ${ }^{29}$ However, P479L homozygosity is present in more than $50 \%$ of adults in several of the indigenous populations where it has been found, and the P479L variant may have experienced a recent selective sweep in these populations. ${ }^{2}$ For a causal association with infant death to be present, one would have to assume either (i) that the reproductive success of adults with P479L homozygosity is extremely high compared to those with other CPT1A genotypes due to an effect of the P479L variant or another variant in linkage disequilibrium $^{29}$ or (ii) that the environmental circumstances in which the genotype leads to a higher risk of infant death represent a very recent change.

There has been a shift away from the traditional diet in favor of a Western diet among Inuit and AN populations, ${ }^{30-32}$ and one might speculate that a Western diet is deleterious to P479L homozygous infants. Traditional foods in AN communities are high in polyunsaturated fatty acids, which may historically have upregulated CPT1A expression ${ }^{21}$ and compensated for any protein instability. ${ }^{13,14}$ In fact, the variant may have been protective $\mathrm{e}^{2,13}$ by reducing accumulation of CPT1A, which in turn would have prevented the overproduction of ketone bodies. However, even if the P479L variant were less adaptive for a Western diet, the effect of a dietary transition would need to be dramatic to account for the proposed impact on infant death, and one might expect a deleterious effect on older children and adults as well. In fact, a study involving Yup'ik people living in southwestern Alaska showed an association between P479L homozygosity and favorable fasting lipid levels and an inverse association between P479L homozygosity and obesity. ${ }^{21}$ Two 
other studies have shown a role of CPT1A in increasing protective lipid profiles related to cardiovascular disease. ${ }^{20,33}$

Overall, the available evidence about the effect of P479L homozygosity on enzyme function and the high prevalence of the genotype among adults in the affected populations reduces the biological plausibility of a causal association between $\mathrm{P} 479 \mathrm{~L}$ homozygosity and infant death.

\section{Alternative explanations for the association between P479L homozygosity and infant death}

A noncausal association between P479L homozygosity and infant death could occur if other risk factors for infant death are more prevalent among the indigenous populations in which the P479L variant is prevalent. The available evidence suggests several possible factors.

Infant sleeping practices. The majority (70\%) of recorded deaths in the Nunavut study occurred among infants with at least two sleeping risk factors, including sleeping in the prone position or in bed-sharing arrangements, and all deaths of P479L homozygous infants had at least one sleep-related risk factor. ${ }^{23}$ The other three studies did not report on infant sleeping practices. ${ }^{1,3,8}$ An association between genotype and infant death may reflect sleeping practices among populations with a high prevalence of the P479L variant rather than a causal association.

High infant death rates among indigenous populations. More generally, population-based studies document an increased infant death rate among indigenous populations across North America (overall 1.5- to 2.5-fold), as well as among many indigenous populations globally. ${ }^{34-37}$ Risk factors among American Indian and Alaska Native (AI/ AN) populations include higher rates of low birth weight (possibly related to limitations in prenatal care), ${ }^{34,36,38}$ lower respiratory infections, ${ }^{38,39}$ maternal education of less than 12 years, ${ }^{38}$ unmarried mother and/or the father's name not on the birth certificate, ${ }^{38}$ prenatal smoking or alcohol use by the mother, ${ }^{38,40}$ and reduced air turnover in the home. ${ }^{23}$ Compared with white infants living in rural regions, rural AI/AN infants are more likely to die from complications of congenital malformations, respiratory infection, sudden infant death syndrome, unintentional injury, diseases of the circulatory system, newborn bacterial sepsis, and homicide. ${ }^{37,41}$ Children in the circumpolar areas of Canada have high rates of invasive Haemophilus influenzae infection, leading to 0.65 deaths per 1,000 live births in Nunavut. ${ }^{23}$ Infants in Nunavut experience an OR of 8.79 for death due to infection compared to Canadian infants outside of Ontario. ${ }^{4}$

\section{Implications}

The available studies point to a number of social factors that could contribute to higher infant mortality rates among populations with a high prevalence of the P479L variant. Together with data on enzyme function and genotype prevalence, these data indicate that a noncausal association between P479L homozygosity and infant death is plausible. Although further investigation of the genotype is warranted, future research should also incorporate careful assessment of potential confounders that may in fact be the causal factors leading to higher rates of infant death in northern indigenous populations.

\section{PENETRANCE}

As described above, the available evidence raises questions about a causal association between P479L homozygosity and infant death. However, even if a causal association were established, the high prevalence of P479L homozygosity among adults in the Canadian and Greenlandic Inuit and AN populations studied ${ }^{20-22}$ indicates that the genotype would have very low penetrance. P479L homozygosity is found in 50 to $70 \%$ among adults in the affected populations and at frequencies not substantially different from that in newborns., ${ }^{2,21}$

\section{POLICY IMPLICATIONS}

\section{Potential negative consequences of unproven interventions}

Public health messaging about CPT1A based on presumed biological implications of the association between P479L homozygosity and infant death is premature. A public video campaign to raise awareness about the variant and to promote dietary interventions has been developed ${ }^{7}$ and disseminated in clinics throughout Alaska; however, the value of efforts to change infant feeding practices is unproven and could have unintended negative consequences. For example, increased feeding with nontraditional carbohydrate-rich diets could lead to weight gain, which may be a concern for a population that is already combating problems with obesity (affecting 58\% of AN women and $19 \%$ of AN men in western and southwestern Alaska) and a prevalence of type 2 diabetes that has increased 300 -fold since the 1980s among AN populations in parts of western Alaska. ${ }^{42,43}$ Public health messages regarding an increased risk of infant mortality could also lead to parental worry and frequent visits to health-care providers.

\section{Newborn screening}

Newborn screening for infants who have severe CPT1A deficiency offers an important opportunity to initiate life-saving dietary interventions. ${ }^{44}$ Such screening became possible in the early 2000s, when the US and Canadian newborn-screening systems adopted tandem mass spectrometry (MS/MS) analysis that can determine $\mathrm{C} 0 /(\mathrm{C} 16+\mathrm{C} 18)$ ratios. Although MS/ MS is effective at identifying infants with homozygosity for the p.G710E variant resulting in classic CPT1A deficiency, detection of P479L homozygosity is less efficient due to median C0/ $(\mathrm{C} 16+\mathrm{C} 18)$ ratios below those published for classic CPT1A deficiency. ${ }^{3,16,45}$ All of the AN infants identified in published literature with CPT1A deficiency have been identified during follow-up from other abnormal results and were not initially identified from abnormal $\mathrm{C} 0 /(\mathrm{C} 16+\mathrm{C} 18)$ ratios in $\mathrm{MS} / \mathrm{MS}$ screening. ${ }^{46}$ Presumably, the lower ratios and reduced detection 
reflect the partial enzyme activity associated with P479L homozygosity. They also point to uncertainty about the benefits of early detection of infants with P479L homozygosity.

Although newborn screening can identify infants for early lifesaving interventions, it also may falsely identify patients who do not need and will not benefit from these interventions. The value of detecting infants with P479L homozygosity, or other nonclassic forms of CPT1A deficiency, is unproven. The key question in addressing this issue, which is unresolved by current data, is whether the association between P479L homozygosity and infant death can inform targeted interventions that reduce risk.

\section{Further evaluation of the CPT1A association}

Although a causal association between P479L homozygosity and infant death seems unlikely, further research is needed. In particular, if a biological basis related to CPT1A enzyme activity could be established for the association, interventions based on this knowledge, possibly including changes in the frequency and content of infant feeding practices, might reduce mortality. ${ }^{46}$ In addition, establishing a causal association might provide a justification-currently lacking-for focusing prevention efforts on infants with P479L homozygosity. It is worth noting, however, that even if a causal association is proven, prevention efforts might still be optimally directed toward mediating factors affecting all infants. For example, if death in infants with P479L homozygosity is mediated by respiratory infection, reducing pathogen exposure might be the most effective intervention approach.

\section{Additional risk factors for infant death}

Whether or not the association between P479L homozygosity and infant death reflects a role for the genotype in a causal pathway, there is a need for a better understanding of other factors contributing to infant death in northern indigenous populations. As described above, these could include sleepassociated risk factors, higher exposure to respiratory viruses, inadequate access to health care, and adoption of a Western diet. ${ }^{8,36,39-41}$ Clarifying the relative importance of these factors and the interactions (if any) among them or with P479L homozygosity is essential to designing appropriate interventions to reduce risk.

\section{RESEARCH AGENDA}

A deeper understanding of all risk factors for infant death present among populations with a high frequency of $\mathrm{P} 479 \mathrm{~L}$ homozygosity is urgently needed. Interventions involving sleeping practices and exposure to respiratory pathogens, as well as increased efforts to improve access to prenatal care and social support for pregnant women and new mothers, may be the most effective approaches to reducing infant deaths. These approaches represent the important public health priority. However, attention must also be paid to the question of $\mathrm{P} 479 \mathrm{~L}$ homozygosity and, in particular, whether preventive efforts for infants with this genotype are warranted.
Given the limited data available at this time, a fundamental policy concern is to ensure the implementation of a research agenda that can determine whether P479L homozygosity contributes to infant death in the context of a more comprehensive assessment of all potential risk factors and, if so, by what biological mechanisms. Population-based research incorporating the evaluation of both known and suspected risk factors for infant death is needed. Studies need to be designed and adequately powered to evaluate potential confounders such as access to prenatal care, infant sleep practices, and living conditions associated with an increased likelihood of respiratory pathogen exposure. Cross-border studies of populations residing in Alaska and northern and western Canada may be needed to achieve adequate sample sizes. From these studies, potential interventions could be identified for further assessment.

A critical element in a successful approach will be the inclusion of leadership from the affected AN and Inuit populations in the development and implementation of the research to ensure both the identification and assessment of risk factors for infant death and community support for interventional trials. Collaborative research partnerships among tribal communities and university-based researchers to support genomic research utilizing the principles of community-based participatory research ${ }^{47-49}$ provide a model for pursuing this important research agenda.

\section{ACKNOWLEDGMENTS}

We thank Bert Boyer, C. Ronald Scott, and Kenneth Thummel for their advice and review of the manuscript. This work was supported by the National Human Genome Research Institute and the National Institute of General Medical Sciences at the National Institute of Health (NHGRI P50 HG003374, NIGMS U01 GM092676, NHGRI K01 HG008818, and NIGMS R24 GM61374).

\section{DISCLOSURE}

The authors declare no conflict of interest.

\section{REFERENCES}

1. Gessner BD, Gillingham MB, Birch S, Wood T, Koeller DM. Evidence for an association between infant mortality and a carnitine palmitoyltransferase $1 \mathrm{~A}$ genetic variant. Pediatrics 2010;126:945-951.

2. Clemente FJ, Cardona A, Inchley CE, et al. A selective sweep on a deleterious mutation in CPT1A in arctic populations. Am J Hum Genet 2014; 95:584-589.

3. Sinclair GB, Collins S, Popescu O, McFadden D, Arbour L, Vallance HD. Carnitine palmitoyltransferase I and sudden unexpected infant death in British Columbia First Nations. Pediatrics 2012;130:e1162-e1169.

4. Collins SA, Surmala P, Osborne G, et al. Causes and risk factors for infant mortality in Nunavut, Canada 1999-2011. BMC Pediatr 2012;12:190.

5. Prasad C, Johnson JP, Bonnefont JP, et al. Hepatic carnitine palmitoyl transferase 1 (CPT1 A) deficiency in North American Hutterites (Canadian and American): evidence for a founder effect and results of a pilot study on a DNA-based newborn screening program. Mol Genet Metab 2001;73:55-63.

6. Prip-Buus C, Thuillier L, Abadi N, et al. Molecular and enzymatic characterization of a unique carnitine palmitoyltransferase 1A mutation in the Hutterite community. Mol Genet Metab 2001;73:46-54.

7. Western States Genetics Collaborative Health Resources and Services Administration, State of Alaska Department of Health and Social Services, Norton South Health Corporation. The Other Energy Crisis: Arctic Variant CPT1A. https://www.youtube.com/watch?v=g-JRZ7PO3yk. Published 25 June 2013; Accessed 8 February 2016. 
8. Gessner BD, Wood T, Johnson MA, Richards CS, Koeller DM. Evidence for an association between infant mortality and homozygosity for the arctic variant of carnitine palmitoyltransferase 1A. Genet Med 2016;18:933-939.

9. McGarry JD, Brown NF. The mitochondrial carnitine palmitoyltransferase system. From concept to molecular analysis. Eur J Biochem 1997;244:1-14.

10. Jogl G, Hsiao YS, Tong L. Structure and function of carnitine acyltransferases. Ann N Y Acad Sci 2004;1033:17-29.

11. Bonnefont JP, Djouadi F, Prip-Buus C, Gobin S, Munnich A, Bastin J. Carnitine palmitoyltransferases 1 and 2: biochemical, molecular and medical aspects. Mol Aspects Med 2004;25:495-520.

12. Flachs $\mathrm{P}$, Horakova $\mathrm{O}, \mathrm{Brauner} \mathrm{P}$, et al. Polyunsaturated fatty acids of marine origin upregulate mitochondrial biogenesis and induce beta-oxidation in white fat. Diabetologia 2005;48:2365-2375.

13. Greenberg CR, Dilling LA, Thompson GR, et al. The paradox of the carnitine palmitoyltransferase type la P479L variant in Canadian Aboriginal populations. Mol Genet Metab 2009;96:201-207.

14. Ide T, Kobayashi H, Ashakumary L, et al. Comparative effects of perilla and fish oils on the activity and gene expression of fatty acid oxidation enzymes in rat liver. Biochim Biophys Acta 2000;1485:23-35.

15. Region 4 Stork. MS/MS Collaborative Project. 2016. https://www. clir-r4s.org/ https://www.nbstrn.org/research-tools/lab-performance-database. Accessed 24 August 2016.

16. McHugh D, Cameron CA, Abdenur JE, et al. Clinical validation of cutoff target ranges in newborn screening of metabolic disorders by tandem mass spectrometry: a worldwide collaborative project. Genet Med 2011;13:230-254.

17. Canadian Organization for Rare Disorders. Newborn Screening in Canada Status Report. 2015. https://www.raredisorders.ca/content/uploads/CanadaNBS-status-updated-Sept.-3-2015.pdf. Accessed 23 September 2016.

18. National Newborn Screening and Genetics Resource Center. National Newborn Screening Status Report. 2014. http://genes-r-us.uthscsa.edu/sites/genes-r-us/ files/nbsdisorders.pdf. Accessed 23 September 2016.

19. Brown NF, Mullur RS, Subramanian I, et al. Molecular characterization of L-CPT I deficiency in six patients: insights into function of the native enzyme. J Lipid Res 2001;42:1134-1142.

20. Rajakumar C, Ban MR, Cao H, Young TK, Bjerregaard P, Hegele RA. Carnitine palmitoyltransferase IA polymorphism P479L is common in Greenland Inuit and is associated with elevated plasma apolipoprotein A-I. J Lipid Res 2009;50:1223-1228.

21. Lemas DJ, Wiener HW, O'Brien DM, et al. Genetic polymorphisms in carnitine palmitoyltransferase $1 \mathrm{~A}$ gene are associated with variation in body composition and fasting lipid traits in Yup'ik Eskimos. J Lipid Res 2012;53:175-184.

22. Collins SA, Sinclair G, McIntosh S, et al. Carnitine palmitoyltransferase $1 A$ (CPT1A) P479L prevalence in live newborns in Yukon, Northwest Territories, and Nunavut. Mol Genet Metab 2010;101:200-204.

23. Collins SA, Surmala P, Osborne G, et al. Causes and risk factors for infant mortality in Nunavut, Canada 1999-2011. BMC Pediatrics 2012:12:1-8.

24. Koepsell TD, Weiss NS. Epidemiologic Methods: Studying the Occurrence of Illness. Oxford University Press: New York, 2003.

25. Heiman GA, Hodge SE, Gorroochurn P, Zhang J, Greenberg DA. Effect of population stratification on case-control association studies. I. Elevation in false positive rates and comparison to confounding risk ratios (a simulation study). Hum Hered 2004; 58:30-39.

26. Gessner BD, Gillingham MB, Wood T, Koeller DM. Association of a genetic variant of carnitine palmitoyltransferase $1 \mathrm{~A}$ with infections in Alaska Native children. J Pediatr 2013;163:1716-1721.

27. Gillingham MB, Hirschfeld M, Lowe S, et al. Impaired fasting tolerance among Alaska native children with a common carnitine palmitoyltransferase $1 \mathrm{~A}$ sequence variant. Mol Genet Metab 2011;104:261-264.

28. Gobin S, Bonnefont JP, Prip-Buus $C$, et al. Organization of the human liver carnitine palmitoyltransferase 1 gene (CPT1A) and identification of novel mutations in hypoketotic hypoglycaemia. Hum Genet 2002;111:179-189.

29. Hartl DL, Clark AG. Principles of Population Genetics. 4th edn. Sinauer Associates: Sunderland, MA, 2007
30. Bersamin A, Luick BR, Ruppert E, Stern JS, Zidenberg-Cherr S. Diet quality among Yup'ik Eskimos living in rural communities is low: the Center for Alaska Native Health Research Pilot Study. J Am Diet Assoc 2006;106: 1055-1063.

31. Sheehy T, Roache C, Sharma S. Eating habits of a population undergoing a rapid dietary transition: portion sizes of traditional and non-traditional foods and beverages consumed by Inuit adults in Nunavut, Canada. Nutr J 2013; $12: 70$.

32. O'Brien DM, Thummel KE, Bulkow LR, et al. Declines in traditional marine food intake and vitamin D levels from the 1960s to present in young Alaska Native women. Public Health Nutr 2016; e-pub ahead of print 28 July 2016.

33. Voruganti VS, Higgins PB, Ebbesson SO, et al. Variants in CPT1A, FADS1, and FADS2 are associated with higher levels of estimated plasma and erythrocyte delta-5 desaturases in Alaskan Eskimos. Front Genet 2012;3:86.

34. Spong CY, lams J, Goldenberg R, Hauck FR, Willinger M. Disparities in perinatal medicine: preterm birth, stillbirth, and infant mortality. Obstet Gynecol 2011;117:948-955.

35. Tomashek KM, Qin C, Hsia J, lyasu S, Barfield WD, Flowers LM. Infant mortality trends and differences between American Indian/Alaska Native infants and white infants in the United States, 1989-1991 and 1998-2000. Am J Public Health 2006;96:2222-2227.

36. Hoyert DL, Mathews TJ, Menacker F, Strobino DM, Guyer B. Annual summary of vital statistics: 2004. Pediatrics 2006;117:168-183.

37. Wong CA, Gachupin FC, Holman RC, et al. American Indian and Alaska Native infant and pediatric mortality, United States, 1999-2009. Am J Public Health 2014:104(suppl 3):S320-328.

38. Postneonatal mortality among Alaska Native infants-Alaska, 1989-2009. Morb Mortal Wkly Rep 2012:61:1-5.

39. Singleton RJ, Wirsing EA, Haberling DL, et al. Risk factors for lower respiratory tract infection death among infants in the United States, 1999-2004. Pediatrics 2009;124:e768-e776.

40. Blabey MH, Gessner BD. Three maternal risk factors associated with elevated risk of postneonatal mortality among Alaska native population. Matern Child Health J 2009;13:222-230.

41. Baldwin LM, Grossman DC, Murowchick E, et al. Trends in perinatal and infant health disparities between rural American Indians and Alaska natives and rural Whites. Am J Public Health 2009;99:638-646.

42. Koller KR, Metzger JS, Jolly SE, et al. Cardiometabolic correlates of low type 2 diabetes incidence in western Alaska Native people-the WATCH study. Diabetes Res Clin Pract 2015;108:423-431.

43. Hopkins SE, Austin MA, Metzger JS, et al. Sex differences in obesity prevalence and cardiometabolic factors among Western Alaska Native people. Nutr Metab Cardiovasc Dis 2015;25:312-318.

44. Fingerhut R, Röschinger W, Muntau AC, et al. Hepatic carnitine palmitoyltransferase I deficiency: acylcarnitine profiles in blood spots are highly specific. Clin Chem 2001:47:1763-1768.

45. Gessner BD, Gillingham MB, Johnson MA, et al. Prevalence and distribution of the $c .1436 \mathrm{C} \rightarrow$ T sequence variant of carnitine palmitoyltransferase $1 \mathrm{~A}$ among Alaska Native infants. J Pediatr 2011:158:124-129.

46. Koeller D, Wood T. Carnitine palmitoyltransferase 1A deficiency. Alaska Maternal Child Health and Immunization Conference, Anchorage, AK, 23 September 2008.

47. Woodahl EL, Lesko LJ, Hopkins S, Robinson RF, Thummel KE, Burke W. Pharmacogenetic research in partnership with American Indian and Alaska Native communities. Pharmacogenomics 2014;15:1235-1241.

48. Arbour L, Cook D. DNA on loan: issues to consider when carrying out genetic research with aboriginal families and communities. Community Genet 2006;9:153-160

49. Mohatt GV, Plaetke R, Klejka J, et al.; Center for Alaska Native Health Research The Center for Alaska Native Health Research Study: a community-based participatory research study of obesity and chronic disease-related protective and risk factors. Int J Circumpolar Health 2007;66:8-18. 